\title{
The transmembrane chemokines CXCL16 and CX3CL1 and their receptors are expressed in human meningiomas
}

\author{
GU LI $^{1,3^{*}}$, KIRSTEN HATTERMANN ${ }^{2 *}$, ROLF MENTLEIN ${ }^{2}$, \\ H. MAXIMILIAN MEHDORN ${ }^{1}$ and JANKA HELD-FEINDT ${ }^{1}$ \\ ${ }^{1}$ Department of Neurosurgery, University of Schleswig-Holstein Medical Center, Arnold-Heller-Str. 3, \\ $24105 \mathrm{Kiel}$; ${ }^{2}$ Department of Anatomy, University of Kiel, Otto-Hahn-Platz 8, 24118 Kiel, Germany
}

Received August 13, 2012; Accepted October 26, 2012

DOI: $10.3892 /$ or.2012.2164

\begin{abstract}
Meningiomas are common slowly growing benign tumors, however, anaplastic meningiomas have an aggressive biological and clinical behavior associated with high rates of recurrence and unfavorable prognosis. Since the molecular mechanisms involved in progression of meningiomas are not yet fully understood and recent investigations have suggested a possible role of chemokines in tumor biology, the aim of the study was to investigate the expression of CX3CL1/CX3CR1 and CXCL16/CXCR6 on mRNA and protein level in human meningiomas. Quantitative reverse-transcription polymerase chain reaction, immunohistochemistry and double immunostaining techniques were used for the investigations. We showed that mRNA and protein expression of the chemokine/ receptor pairs CX3CL1/CX3CR1 and CXCL16/CXCR6 were detectable in human meningioma samples. Double immunostaining revealed that the chemokines/receptors were predominantly expressed in the tumor cells themselves, in infiltrating microglia cells/macrophages and endothelial cells of blood vessels. Nevertheless, not all cells of different kinds were positive for different chemokine/receptors. Of note, in
\end{abstract}

Correspondence to: Dr Janka Held-Feindt, Department of Neurosurgery, University of Schleswig-Holstein Medical Center, Campus Kiel, Arnold-Heller-Str. 3, Building 41, 24105 Kiel, Germany

E-mail: held-feindtj@nch.uni-kiel.de

Present address: ${ }^{3}$ Department of Neurosurgery, the First Affiliated Hospital, College of Medicine, Zhejiang University, 79 Qingchun Road, Zhejiang, Hangzhou 310003, P.R. China

*Contributed equally

Abbreviations: $\mathrm{C}_{\mathrm{T}}$, cycle of threshold; EMA, epithelial membrane antigen; GAPDH, glycerinaldehyde-3-phosphate-dehydrogenase; IHC, immunohistochemistry; qRT-PCR, quantitative reversetranscription polymerase chain reaction; $\mathrm{VWF}$, von Willebrand factor protein; WHO, World Health Organization

Key words: chemokine, CXCL16/CXCR6, CX3CL1/CX3CR1, meningioma comparison to more benign meningioma samples, CX3CR1 and CXCL16 were found to be expressed at lower levels in anaplastic variants. Moreover, a positive correlation between expression levels of ligands and corresponding receptors could be observed for some malignancy grades. Taken together, these results showed that chemokines and their receptors are involved in the pathogenesis of human meningiomas. Our results provide an interesting basis for further investigations that should be performed to characterize the functional roles of chemokines and their receptors in human meningiomas, and also enhance future therapeutic design.

\section{Introduction}

Meningiomas are neoplasms derived from arachnoidea cells and they can be found in the dura mater. Meningiomas are considered to be the second most common intracranial tumors and account for $13-26 \%$ of all primary brain tumors (1). Most (approximately 90\%) of the meningiomas are slowly growing benign tumors, classified as World Health Organization (WHO) grade I (2). However, atypical meningiomas (WHO grade II), which are characterized by increased cellularity and mitotic activity, account for approximately $8 \%$ of this tumor type. Anaplastic variants (WHO grade III), which make up approximately $2 \%$, show a more aggressive biological behavior and are associated with a high risk of local recurrence and a poor clinical outcome $(1,3)$. Surgery is the mainstay of treatment, with the likelihood of recurrence being inversely related to the extent of resection $(3,4)$. The recurrence rate for meningiomas is on average $10 \%$ after a complete resection and up to $50 \%$ after an incomplete resection (5).

In addition, recurrence rates are higher for the more aggressive histological variants, with 5-year recurrence rates of $38 \%$ for atypical meningiomas and $78 \%$ for malignant meningiomas (4). When patients were grouped by histological type of tumors, those with benign meningiomas had an overall 5-year survival rate of $70 \%$, whereas the overall 5-year survival rates in patients with atypical and anaplastic meningiomas were 75 and $55 \%$, respectively (6). Furthermore, accepted alternative therapies for patients who have failed surgical intervention are currently limited to radiotherapy which has been shown to delay recurrence $(3,7)$. Currently, there are no pharmaceutical agents that are routinely used for adjuvant therapy. 
Chemokines are 8- to 12-kDa peptides that bind to specific G-protein-coupled, seven-span transmembrane receptors on the plasma membrane of target cells. Most chemokines bind to multiple receptors, and the same receptor may bind to more than one chemokine $(8,9)$. Chemokines are classified into four major subfamilies on the basis of the motif of the first two cysteine residues. They play an essential role in cellular migration and intracellular communication and were originally observed as inducible cytokines facilitating the recruitment of specific leukocyte subsets (10). They are also involved in many other physiological and pathological processes, including neoplasia, in which they play an important role through multiple mechanisms (11-16).

The chemokines CXCL16 (also termed SR-PSOX22) and CX3CL1 (also known as fractalkine or neurotactin) differ from the other known, approximately 50 human chemokines by their exceptional structure: They are synthesized as transmembrane multi-domain molecules consisting of a chemokine domain followed by a glycosylated mucin-like stalk and a single transmembrane helix (17). However, soluble forms of CXCL16 and CX3CL1 are generated by constitutive or induced cleavage (shedding) from the cell membranes through the action of the cell-surface proteases $(14,18)$. As a result, by interacting with their receptors the released soluble forms of CX3CL1 and CXCL16 mainly function as leukocyte chemoattractants.

In non-malignant tissue, CXCL16 is produced by macrophages, dendritic, endothelial and smooth muscle cells. CX3CL1 is produced by IL-1-stimulated endothelial cells and has been shown to mediate migration of monocytes and T lymphocytes $(19,20)$. Since CXCL16 and CX3CL1 are cytokine-inducible chemokines, their expression is associated with a number of human inflammatory diseases including rheumatoid arthritis, atherosclerosis, coronary artery disease and liver injury. However, high CXCL16 and CX3CL1 expression have been found in several types of cancer $(15,21-29)$. CX3CR1 (also termed RBS11 or V28) is the highly specific receptor for CX3CL1 $(30,31)$. In the periphery CX3CR1 is expressed on monocytes, dendritic cells, $\mathrm{T}$ cell subsets, $\mathrm{CD} 16$-positive natural killer cells and platelets (32). The CXCL16 receptor CXCR6 (also termed Bonzo, TYMSTR or STRL33) is expressed by CD4-positive effector memory T cell subsets, V $\alpha 24$-positive natural killer $\mathrm{T}$ cells, bone marrow plasma cells and myeloma cells (33-35).

Although a role for CXCL16/CXCR6 and CX3CL1/ CX3CR1 in tumorigenesis has been established little is known about the expression of these chemokines and their receptors in human meningiomas. Therefore, the purpose of this study was to investigate the expression of CXCL16 and CX3CL1 on mRNA and protein level and to determine the expression of their receptors in meningiomas of different malignant grades.

\section{Materials and methods}

Tumor specimens. Meningioma samples were surgical dissected tissues from the Department of Neurosurgery (Kiel, Germany) and were obtained in accordance with the Helsinki Declaration of 1975 and with approval of the ethics committee of the University of Kiel. Tumors were classified according to the WHO criteria into the various subtypes of benign meningiomas and atypical or anaplastic meningiomas (1). The diagnosis was established by a neuropathologist. In this study, samples of 10 WHO I meningiomas were included (9 meningothelial and 1 fibroblastic) from patients with a mean age of $59.8 \pm 13.4$ years ( 8 women, 2 men). Samples from 10 atypical meningiomas (WHO grade II) were from 6 females and 4 males with a mean age of $60.0 \pm 9.4$ years, and 7 anaplastic/ malignant meningioma samples originated from 3 females and 4 males with a mean age of $61.3 \pm 11.1$ years, and one of these anaplastic meningiomas (male, 78 years) was a relapse from a previous meningioma affection. If possible (enough material available), for quantitative RT-PCR, immunohistochemistry and immunofluorescence double-stainings matched probes of individual tumour samples were used. However, due to small sample size and/or tissue integrity of cryosections this was not possible for all tested tissue samples.

Real-time RT-PCR. RNA was isolated with the TRIzol reagent (Invitrogen, Carlsbad, CA, USA), digested by DNase, cDNA synthesized and quantitative real-time RT-PCR (qRTPCR) was performed (36) using TaqMan primer probes (Applied Biosystems, Foster City, CA, USA): $h G A P D H$ (Hs99999905_m1), hCX3CL1 (Hs00171086_m1), hCX3CR1 (Hs00365842_m1), hCXCL16 (Hs00222859_m1), hCXCR6 (Hs00174843_ml). Ten meningiomas grade I, 10 meningiomas grade II, and 7 meningiomas grade III were analyzed by qRT-PCR. The reaction was carried out with the $\mathrm{MyiQ}^{\mathrm{TM}}$ Single Color Real-time PCR Detection System (Bio-Rad, Munich, Germany) and fluorescent data were converted into cycle threshold $\left(\mathrm{C}_{\mathrm{T}}\right)$ measurements. $\Delta \mathrm{C}_{\mathrm{T}}$ values of each sample were calculated as $\mathrm{CT}_{\text {gene of interest }}-\mathrm{CT}_{\mathrm{GAPDH}} \cdot \mathrm{A} \Delta \mathrm{C}_{\mathrm{T}}$ value of 3.33 corresponds to one magnitude lower gene expression compared to GAPDH (glycerinaldehyde-3-phosphate-dehydrogenase). For each gene, logarithmic linear dependence of $\mathrm{C}_{\mathrm{T}}$-values from the numbers of copies was verified by using different amounts of cDNA.

Immunohistochemistry. For examination by immunohistochemistry (IHC), fresh-frozen meningioma tissues of different WHO grades were cut in a freezing cryostat into $6 \mu \mathrm{m}$ sections. The sections were air dried and stored at $-20^{\circ} \mathrm{C}$ until used. IHC was performed using the avidin-biotin-peroxidase complex (ABC) method. The sections were fixed with $4 \%$ para-formaldehyde in Tris-buffered saline (TBS) for $30 \mathrm{~min}$ at room temperature (RT). To block endogenous peroxidase and non-specific binding, $3 \% \mathrm{H}_{2} \mathrm{O}_{2}$ in $0.3 \%$ Triton X-100/ TBS (30 min at RT) and appropriate $10 \%$ normal blocking serum in TBS (60 min at RT; Jackson Immuno Research Laboratories, USA) were used, respectively. Sections were incubated with appropriate dilutions of primary antibodies overnight at $4^{\circ} \mathrm{C}$ (anti-CX3CL1, mouse monoclonal, 1:200, R\&D Systems, Wiesbaden, Germany; anti-CX3CR1, rabbit polyclonal, 1:200, Santa Cruz, CA, USA; anti-CXCL16, goat polyclonal, 1:200, R\&D Systems; anti-CXCR6, mouse monoclonal, 1:50, R\&D Systems). The antibodies were diluted in $0.3 \%$ Triton X-100/TBS and appropriate $2 \%$ normal blocking serum in TBS. Primary antibodies were omitted for negative controls. Additionally, serum-control and isotype-controls (final concentrations similar to corresponding specific primary antibodies) were performed for each primary anti- 

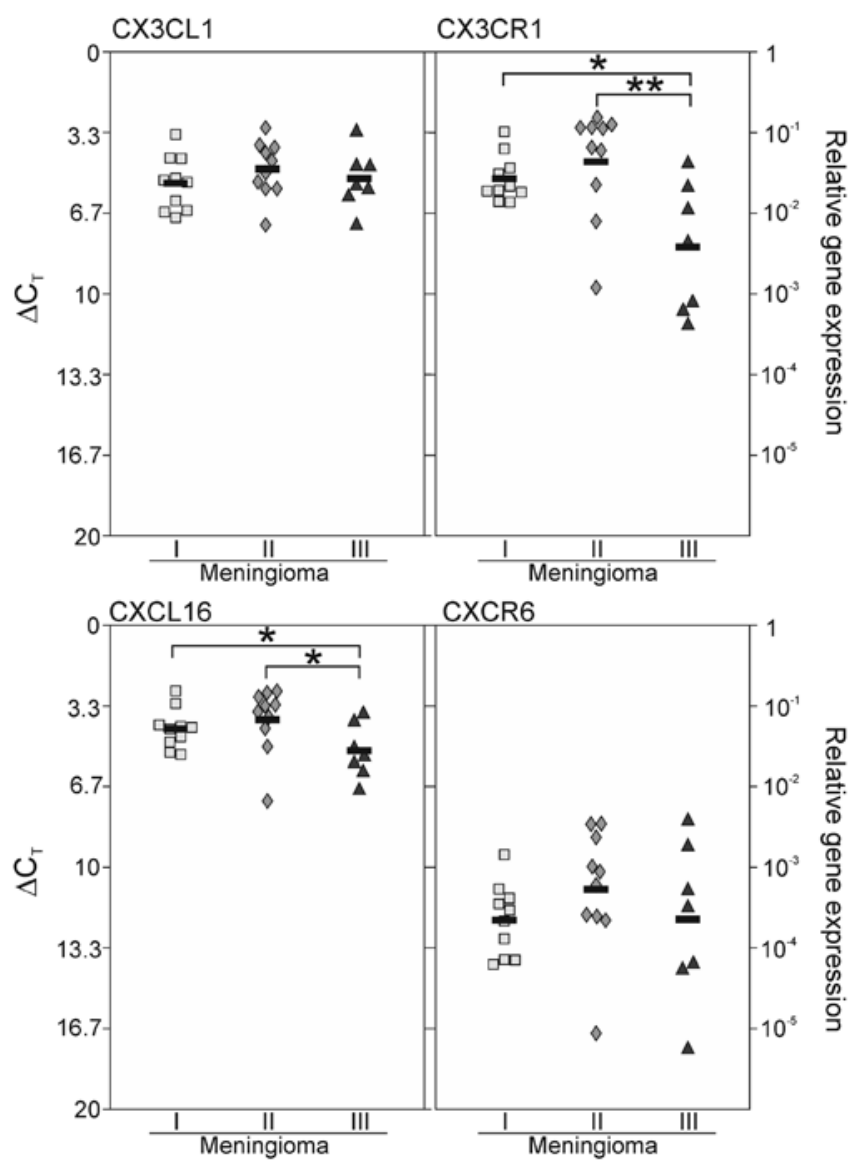

Figure 1. Expression of CX3CL1/CX3CR1 (upper lane) and CXCL16/ CXCR6 (lower lane) in meningiomas of different WHO grades evaluated by quantitative real-time RT-PCR (logarithmic scale, $\Delta \mathrm{CT}=3.3$ corresponds to a 10 -fold difference). Single quadrates, rhombs and triangles indicate one tissue sample; bold lines indicate the mean value of the respective group. Undetectable values were not included in the mean calculation. Although a wide range between single samples occurred, with exception of CXCR6 high expression levels were detected for both chemokine/receptors in different meningioma tissues. Asterisks indicate significant differences between tissues of meningiomas with diverse malignant grades $\left({ }^{*} \mathrm{p}<0.05,{ }^{* *} \mathrm{p}<0.01\right)$.

body [normal mouse IgG, normal rabbit and normal goat IgG (R\&D Systems)]. After washing steps with TBS (10 min for two times), the sections were incubated with corresponding secondary antibody diluted 1:200 in 1.5\% blocking serum/ TBS for $60 \mathrm{~min}$ at RT (biotinylated horse anti-mouse IgG for CX3CL1 and CXCR6, Vector Laboratories, Burlingame, CA, USA; biotinylated rabbit anti-goat IgG for CXCL16, Vector Laboratories; biotinylated donkey anti-rabbit for CX3CR1, Jackson Immuno Research). The signals were amplified using the ABC method with ABC Vectastain ${ }^{\circledR}$ kit (Vector Laboratories). The signal was visualized by incubation with $0.06 \%$ 3,3'-diaminobenzidine-tetrahydrochloride (SigmaAldrich, Munich, Germany) and $0.003 \% \mathrm{H}_{2} \mathrm{O}_{2}$ in $0.1 \mathrm{M}$ Tris- $\mathrm{HCl}(\mathrm{pH}$ 7.6) for $3 \mathrm{~min}$. Then, the slides were counterstained with Mayer's Hemalum (Carl Roth $\mathrm{GmbH}$, Germany) for $60 \mathrm{sec}$. After washing with running tap water for $10 \mathrm{~min}$, the slides were dehydrated step-wise with ethanol (concentration from $70 \% \rightarrow 80 \% \rightarrow 95 \% \rightarrow 95 \% \rightarrow 100 \% \rightarrow 100 \%, 1$ min for each concentration). After clearing in RotiClear (Carl Roth $\mathrm{GmbH}$, $10 \min 3 \mathrm{x}$ ), the slides were mounted with RotiMount ${ }^{\circledR}$ (Carl
Roth $\mathrm{GmbH}$ ) quick-harden mounting medium and used for investigation. Brightfield microscopy with digital photography was performed using a Zeiss microscope and Zeiss camera (Zeiss, Oberkochen, Germany).

Immunofluorescence. Cryostat sections of different meningioma tissues WHO grade I were fixed in acetone/methanol (1:1; $10 \mathrm{~min}$ ) at $-20^{\circ} \mathrm{C}$, washed with Tris-buffered saline plus $0.1 \%$ Tween-20 (TBS-T, 3x, room temperature), washed with $20 \%$, then $70 \%$ ethanol (each 2 min), blocked with Sudan black (1\% in $70 \%$ ethanol) for $10 \mathrm{~min}$, rinsed with $70 \%$ ethanol until dye free, then for 2 min with $20 \%$ ethanol, washed with TBS-T (3x), blocked with $0.1 \%$ bovine serum albumin and $0.2 \%$ glycine in TBS $(1 \mathrm{~h})$, then without washing incubated with primary antibodies in TBS-T at $4^{\circ} \mathrm{C}$ overnight. Primary antibodies were omitted for negative controls. After a washing step (3x TBS-T, $10 \mathrm{~min}$ ) the first secondary antibody was incubated for $1 \mathrm{~h}$ at $37^{\circ} \mathrm{C}$ in darkness. The sections were washed with TBS-T $(3 \mathrm{x}, 10 \mathrm{~min})$. When both primary antibodies were obtained from mouse, an additional blocking step with goat anti-mouse FAB-fragments (1:1000 $1 \mathrm{~h}$, room temperature, from Dianova, Hamburg, Germany) was necessary. The second primary antibody was applied after another washing step (3x TBS-T) and incubated overnight at $4^{\circ} \mathrm{C}$. Second primary antibodies were omitted for negative controls. The slides were washed again ( $3 \mathrm{x}$ TBS-T) and incubated with the second secondary antibody for $1 \mathrm{~h}$ at $37^{\circ} \mathrm{C}$. After washing with TBS-T (1x $10 \mathrm{~min})$, TBS (2x $10 \mathrm{~min})$, nuclei were stained with 4',6-diamidino-2-phenylindole (DAPI; Molecular Probes/ Invitrogen, Life Technologies, Karlsruhe, Germany; 1:30000, 30 min room temperature), washed with TBS (3x) and finally distilled water. After embedding in Immu-Mount (Shandon, Pittsburgh, PA, USA) digital photography was performed using a Zeiss microscope and Zeiss camera (Zeiss).

In combination with anti-epithelial membrane antigen (EMA) (1:500, mouse monoclonal, Dako, Glostrup, Denmark), anti-von Willebrand factor protein (vWF) (1:1000, mouse monoclonal, Santa Cruz) and anti-CD11b (1:100, mouse monoclonal, Santa Cruz), the specific chemokine/receptor antibodies anti-CX3CL1 (1:100, mouse monoclonal, R\&D Systems), anti-CX3CR1 (1:5000, rabbit polyclonal, Biomol, Hamburg, Germany), anti-CXCL16 (1:100, goat polyclonal, R\&D Systems) and anti-CXCR6 (1:50, mouse monoclonal, R\&D Systems) were always stained first with Alexa Fluor 555 coupled secondary antibodies (red, 1:1000, donkey antimouse IgG, donkey anti-rabbit IgG or donkey anti-goat IgG, Invitrogen), the secondary antibody detecting the cellular markers was donkey anti-mouse IgG Alexa Fluor 488 (green, 1:1000, Invitrogen).

Statistical analysis. Statistical methods of Student's t-test with independent samples and bivariate correlation analysis (Pearson correlation coefficients) were used. Significance levels ranged between $\mathrm{p}<0.05$ and $\mathrm{p}<0.01$.

\section{Results}

Expression of CX3CL1/CX3CR1 and CXCL16/CXCR6 in human meningiomas. To evaluate mRNA and protein expression levels of the chemokine/receptor pairs CX3CL1/CX3CR1 

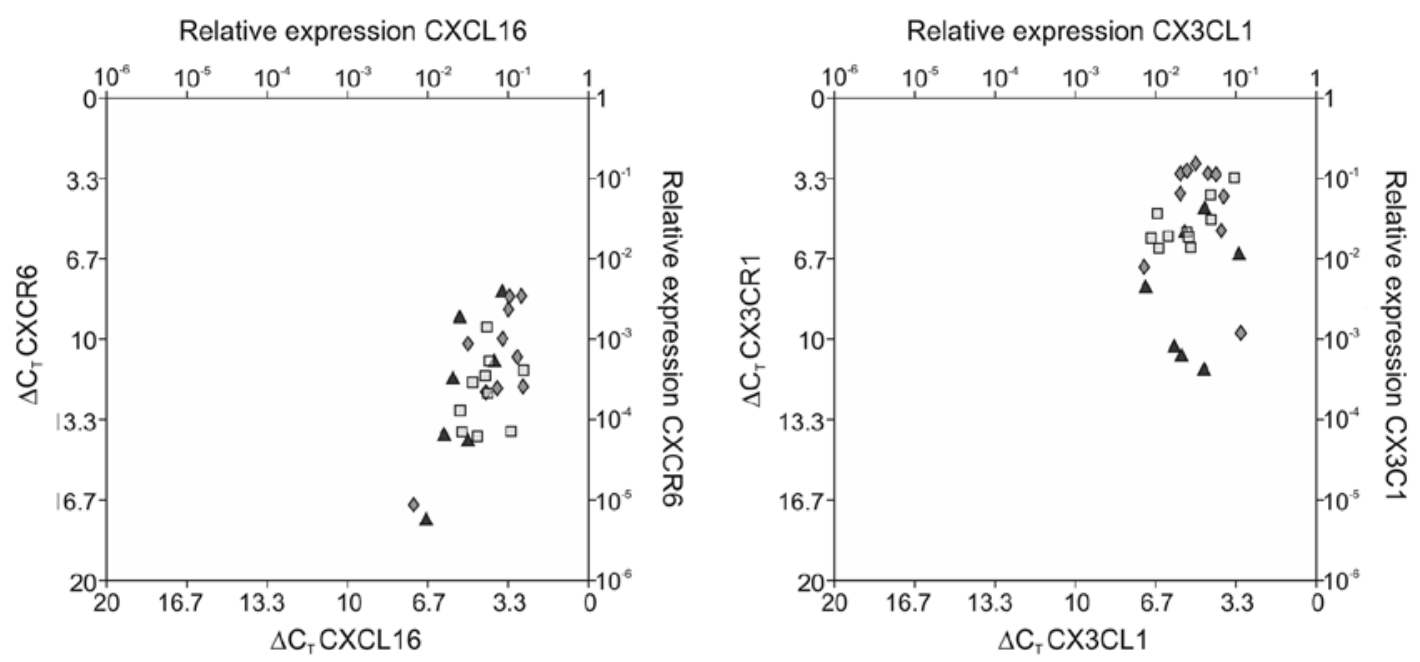

\begin{tabular}{ccccc} 
& \multicolumn{2}{c}{ CXCL16 - CXCR6 } & \multicolumn{2}{c}{ CX3CL1 - CX3CR1 } \\
\cline { 2 - 5 } & $\mathrm{r}$ & $\mathrm{P}$ & $\mathrm{r}$ & $\mathrm{P}$ \\
\hline $\mathrm{I}$ & 0.26 & $>0.05$ & 0.70 & $<0.05$ \\
\hline$\| \triangleright$ & 0.77 & $<0.01$ & -0.21 & $>0.05$ \\
\hline$\| \Delta$ & 0.76 & $<0.05$ & 0.25 & $>0.05$ \\
\hline$I+\|+\| \mathrm{II}$ & 0.66 & $<0.01$ & 0.14 & $>0.05$ \\
\hline
\end{tabular}

Figure 2. Bivariate correlation analysis of chemokine/receptor pairs. $\Delta \mathrm{C}_{\mathrm{T}}$ values of CX3CL1 or CXCL16 were plotted against their respective receptors, and results of bivariate Pearson's correlation analysis of different meningioma groups are shown. Positive correlation was obtained for CXCL16/CXCR6 in meningiomas grades II and III and when all WHO grades were included into the analysis. For CX3CL1/CX3CR1 positive correlation was observed for the meningioma WHO grade I group.

and CXCL16/CXCR6 in human meningiomas of different WHO grades qRT-PCR and immunohistochemistry of different tumors were performed. Results are shown in Figs. 1-3.

For the chemokine ligands CX3CL1 and CXCL16 high mRNA expression levels were detectable in all meningioma samples analysed. The normalized averaged $\Delta \mathrm{CT}$ values were 5.43, 4.84 and 5.23 for CX3CL1 and 4.28, 3.90 and 5.18 for CXCL16 in meningiomas of WHO grades I, II and III, respectively (Fig. 1). In case of CXCL16, expression in meningiomas of WHO grade III was significantly lower than for both other groups $(\mathrm{p}<0.05)$. Although a wide range between single samples occurred, CX3CR1 was also found to be abundantly expressed in human meningiomas. The normalized averaged $\Delta \mathrm{CT}$ values were 5.23, 4.54 and 8.06 in meningiomas of $\mathrm{WHO}$ grades I, II and III, respectively (Fig. 1), and again, expression in WHO grade III meningiomas was significantly lower compared to grade I $(\mathrm{p}<0.05)$ and II $(\mathrm{p}<0.01)$ samples. In contrast, CXCR6 showed much lower expression in different tumor samples (averaged $\Delta \mathrm{CT}$ values were 12.18, 10.91 and 12.15 for meningiomas grades I-III, respectively).

To evaluate whether a correlation between the expression of CX3CL1 and its receptor CX3CR1 as well as of CXCL16 and its receptor CXCR6 in different meningioma samples occurred a bivariate correlation analysis (Pearson correlation coefficients) of qRT-PCR results was performed (Fig. 2). Statistically significant positive correlations between expression levels of CXCL16 and CXCR6 were found in meningiomas WHO grade II ( $\mathrm{r}=0.77$, $\mathrm{p}<0.01)$ and III $(\mathrm{r}=0.76, \mathrm{p}<0.05)$ and if all WHO grades were taken together $(\mathrm{r}=0.66, \mathrm{p}<0.01)$.

For CX3CL1/CX3CR1 a positive correlation was found only for meningioma grade I samples $(r=0.70, p<0.05)$. As proven by immunohistochemistry, expression of the chemokine/ receptor pairs CX3CL1/CX3CR1 and CXCL16/CXCR6 were also detectable on protein levels in human meningiomas of different WHO grades (Fig. 3, positive stained regions/cells indicated by arrows). Additionally, in all analysed meningiomas positive stained regions / cells were separated by unstained ones (Fig. 3).

In summary, mRNA and protein expression of the chemokine/receptor pairs CX3CL1/CX3CR1 and CXCL16/CXCR6 were detectable in human meningioma samples, and in some cases a positive correlation between expression levels of ligands and corresponding receptors could be observed for some malignancy grades.

Cellular targets of CX3CL1/CX3CR1 and CXCL16/CXCR6 in human meningiomas. To investigate the expression of CX3CL1/CX3CR1 and CXCL16/CXCR6 in different cell subsets within the tumors, co-stainings with anti-epithelial membrane antigen (EMA), anti-von Willebrand factor protein (vWF), and anti-CD11b were performed and analysed by fluorescence microscopy. Meningiomas of WHO grade I were used for investigations. Results are shown in Fig. 4.

It should be mentioned that both staining intensities and amounts of positive regions differed among single samples and within the same sample. For all investigated meningioma samples both CX3CL1/CX3CR1 and CXCL16/CXCR6 co-stained with EMA (Fig. 4). EMA belongs to a heterogeneous population of human milk fat globule proteins which are also present in a variety of epithelial cells of normal and neoplastic types, and serves as a marker for meningiomas. Thus, meningioma cells expressed both CX3CL1/CX3CR1 and CXCL16/CXCR6 (examples for merged regions (yellow) are shown in Fig. 4). Additionally, cells which were solely 


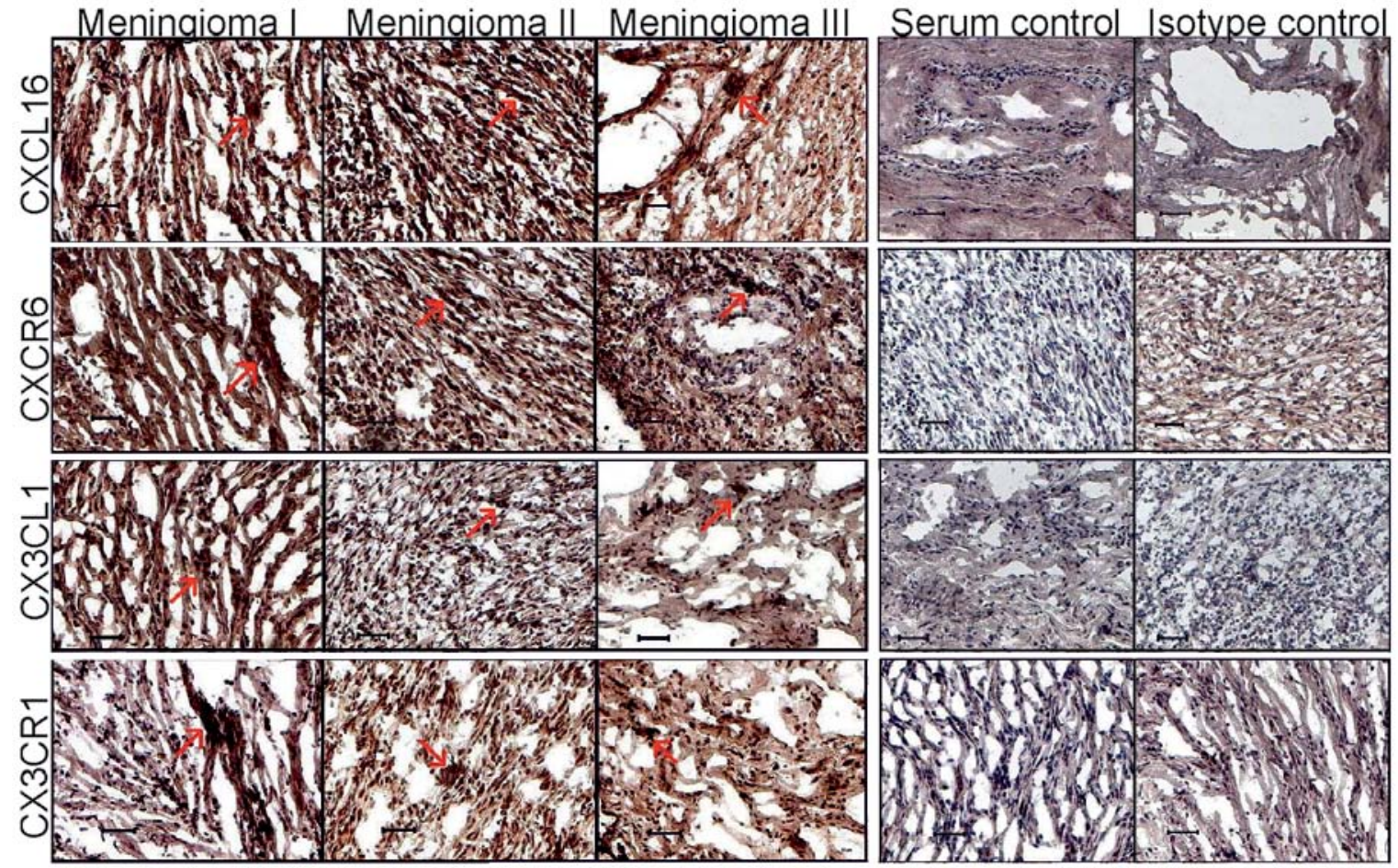

Figure 3. Protein expression of CX3CL1/CX3CR1 and CXCL16/CXCR6 in solid human meningiomas WHO grade I-III sections as shown by immunohistochemistry. In accordance with quantitative real-time RT-PCR results different tumor samples express the chemokines CX3CL1 and CXCL16 and their respective receptors on protein level as shown by exemplary images (arrows indicating positive stained cells/tumor regions). Notably, staining intensity differs between different tumor regions indicating the heterogeneity of the tumor tissues. Serum and isotype controls were performed for every tumor grade, representative examples are shown. Magnification x200 (bars indicate $50 \mu \mathrm{m}$ ).

positive for EMA or the individual chemokine/receptor (or negative for both) existed within the tumor sections (Fig. 4). Expression of CX3CL1, CX3CR1 and CXCL16 was also found in combination with CD11b. No co-staining with CD11b was detectable in case of CXCR6. CD11b, also designated complement component receptor $\alpha 3$ chain or Integrin $\alpha \mathrm{M}$, is a cell adhesion molecule that acts as a receptor for cell surface ligands such as intracellular adhesion molecules. Integrin $\beta 2$ is important in the adherence of neutrophils and monocytes to the stimulated endothelium, which means that in meningioma section predominantly microglial cells/ monocytes should be CD11b positive.

Thereby, in all meningioma sections analysed, investigated chemokines/receptors were found also in microglial cells/ monocytes (Fig. 4; merged yellow regions). Nevertheless, also solely CD11b, CX3CL1/CX3CR1 and CXCL16/CXCR6 stained cells existed within the sections (Fig. 4). Immunofluorescence staining using vWF pointed to a co-staining of CX3CL1 and $\mathrm{vWF}$, whereas other chemokines/receptors were not found in vWF-positive cells. Since vWF is a multimeric glycoprotein that is found in endothelial cells, plasma and platelets, and it is involved in the coagulation of blood at injury sites, for investigated chemokine/receptors only CX3CL1 was detectable in endothelial cells within human meningioma sections (Fig. 4).

Summarized, in human meningioma sections both CX3CL1/CX3CR1 and CXCL16/CXCR6 were found in EMA or, with exception of CXCR6, in CD11b positive cells, respectively, whereas vWF-positive cells were only CX3CL1positive.

\section{Discussion}

Most meningiomas are slowly growing benign tumors, however, anaplastic meningiomas have an aggressive biological and clinical behavior associated with high rates of recurrence and unfavorable prognosis. The molecular mechanisms involved in initiation, proliferation and progression of meningiomas are not yet fully understood. Since recent investigations have suggested a possible role of chemokines in tumor growth, metastasis and host-tumor response (37), the aim of the study was to investigate the expression of CX3CL1/ CX3CR1 and CXCL16/CXCR6 on mRNA and protein level in human meningiomas.

CX3CL1 is a unique CX3C chemokine acting as an adhesion molecule in its membrane form and behaving as a true chemokine in its soluble form. It is one of the most expressed chemokines in the brain $(17,20,38,39)$. Beside neurons, astrocytes are major producers of CX3CL1, whereas its receptor CX3CR1 is predominantly found on microglial cells (40-42). Now we have shown for the first time that CX3CL1/CX3CR1 are also expressed in solid human meningioma samples, localized on the tumor cells themselves, infiltrating microglial cells/macrophages and (for CX3CL1) on endothelial cells. Additionally, CX3CR1 was found to be significantly lower expressed in WHO grade III. The downregulated expression of CX3CR1 mRNA and protein in poorly differentiated anaplastic meningiomas may be indicating the possibility that the CX3CL1/CX3CR1 axis was involved in malignant transformation of meningiomas. Furthermore, a significant 

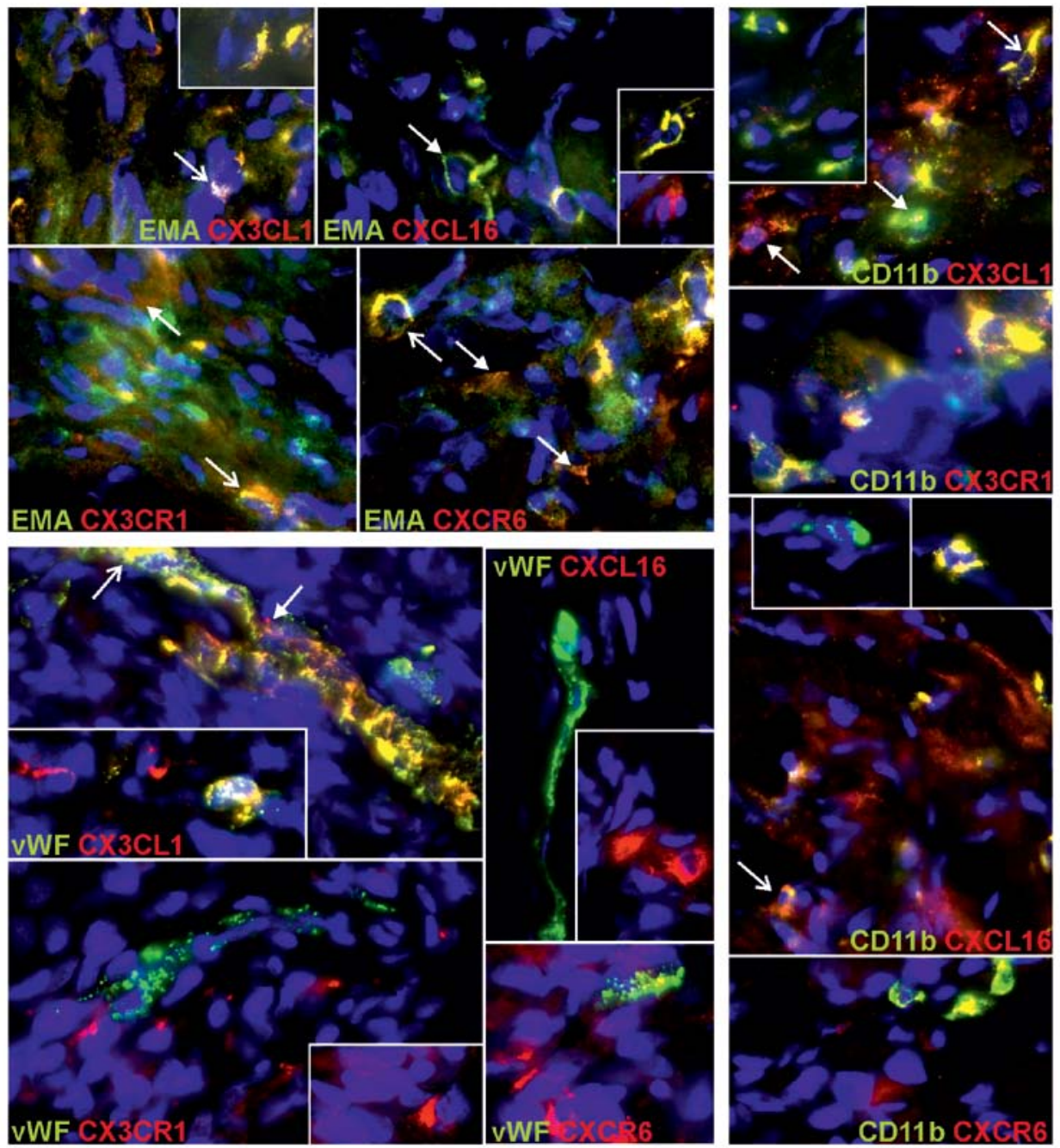

Figure 4. Examples of co-staining of different cellular markers EMA, vWF, CD11b and the chemokine/receptor pairs CX3CL1/CX3CR1 and CXCL16/CXCR6 in meningiomas WHO grade I sections determined by immuno-double-staining. The chemokine/receptor pairs CX3CL1/CX3CR1 and CXCL16/CXCR6 are partly co-stained with epithelial membrane antigen (EMA)-positive tumor cells, but not all tumor cells are positive for these molecules. Staining of CX3CL1/ CX3CR1 and CXCL16 was also detected on CD11b-positive cells indicating microglial cells/monocytes. In contrast, the marker von Willebrand-factor (vWF) for endothelial cells did not merge with CX3CR1, CXCL16 or CXCR6 signals but was partly associated with CX3CL1. Shown is an exemplary choice of different tumor samples. Magnification, x630.

positive correlation between the expression of CX3CL1 and CX3CR1 was observed in meningiomas grade I, but not in grade II and III. Therefore, unbalanced expression of CX3CL1/CX3CR1 might be also associated with a malignant tendency of high-grade meningiomas.

Our results are in accordance with animal models of cancer vaccinations based on the overexpression of CX3CL1 in tumor cells which revealed as a consequence a strong antitumor response (43). The CX3CL1 gene was transduced into murine lung carcinoma cells and could induce antitumor immunity through chemoattraction and activation of $\mathrm{T}$ cells, dendritic cells and natural killer (NK) cells $(43,44)$. Murine colon adenocarcinoma cells $\mathrm{C} 26$ and melanoma B16F10 cells showed that antitumor immune response induced by CX3CL1 gene transfer was depended on NK and T cells activation (28). However, Lavergne et al (45) reported that in an EL-4 lymphoma model, CX3CL1-mediated antitumor effects occurred only via NK cells but not $\mathrm{T}$ cells because this antitumor effect was observed only in T cell- and B cell-deficient Rag1-/- mice, but was ablated in NK cell-deficient beige mice. Therefore, transfer of the CX3CL1 gene into tumor cells could elicit a specific antitumor immunity through acting by its receptor CX3CR 1 capable of inhibiting tumor growth which leads to increased survival of tumor-bearing hosts (46). In hepatocellular carcinoma patients, high expression of CX3CL1/CX3CR1 correlates with better prognosis and fewer recurrences, both local and distant (47).

CXCL16 is the second of the two known transmembrane chemokines, which is not only found on immune cells, but constitutive expression has also been described on fibroblasts, keratinocytes, endothelial cells and cancer cells of different tumor origin $(13-15,17,21,48)$. Additionally, CXCL16 is expressed in the normal human brain at capillary endothelial cells and, pathologically, in malignant human glioma cells and reactive astrocytes in situ and in vitro $(14,18)$. Furthermore, CXCL16 has been detected in human cerebrospinal fluid of patients with inflammatory brain diseases (49). Its receptor CXCR6 was reported to be expressed mainly on immune cells $(34,50,51)$. In the present study we show that the chemokine/ 
receptor pair CXCL16/CXCR6 is expressed in solid human meningioma samples, especially localized on the tumor cells themselves and for CXCL16 on infiltrating microglial cells/ macrophages. If comparing the expression levels of CXCL16 and CXCR6, CXCR6 is up to 100-fold lower expressed. Interestingly, CXCL16 was found to be significantly lower expressed in meningiomas WHO grade III. A positive correlation between the expression of CXCL16 and CXCR6 was observed especially in meningioma samples grade II and III. As indicated for CX3CL1/CX3CR1, these results support the hypothesis that also the CXCL16/CXCR6 axis might be associated with the pathogenesis of human malignant meningiomas.

The expression and functional role of CXCL16 and CXCR6 have been investigated in different types of tumor. Although CXCL16 and CXCR6 mostly seem to be overexpressed in different cancer cells, such as breast cancer tissue $(14,52)$, prostate cancer tissues (53), colorectal cancer tissues (21), schwannomas (15) and pancreatic ductal adenocarcinoma $(54,55)$, it was shown on the contrary that high CXCL16 expression correlated with good prognosis and increased levels of tumor-infiltrating lymphocytes (21). Additionally, CXCL16 was shown to inhibit proliferation in pancreatic carcinoma in vitro and in vivo $(54,55)$. Moreover, an anti-migratory function of CXCL16 in renal cancer cells was demonstrated resulting in the patients with high CXCL16 expression showing significantly longer overall survival times (22). Noteworthy, in accordance with our results presented here for human meningiomas in human rectal cancer, downregulation of CXCL16 has been reported (13).

Summarized, the transmembrane chemokines CX3CL1 and CXCL16 and their corresponding receptors are clearly found to be abundantly expressed in human meningioma samples of different malignant grades. In view of these observations and our results, the CX3CL1/CX3CR1 and CXCL16/CXCR6 axis should be considered as potentially suitable targets for immunoprevention or gene therapy in human meningiomas, especially in anaplastic variants.

\section{Acknowledgements}

This work was supported by the University of Kiel and the 'Deutsche Forschungsgemeinschaft' (HE 3400/5-1; ME 758/10-1). We would like to thank Brigitte Rehmke, Fereshteh Ebrahim, Monika Kunz and Jörg Krause for expert technical assistance.

\section{References}

1. Louis DN, Scheithauer BW, Budka H, von Deimling A and Kepes JJ: Meningiomas. In: World Health Organization Classification of Tumours: Pathology and Genetics of Tumours of the Nervous System. Kleihues P and Cavenee WK (eds). IARC Press, Lyon, pp176-184, 2000.

2. Louis DN, Ohgaki H, Wiestler OD, Cavenee WK, Burger PC, Jouvet A, Scheithauer BW and Kleihues P: The 2007 WHO classification of tumours of the central nervous system. Acta Neuropathol 114: 97-109, 2007.

3. Whittle IR, Smith C, Navoo P and Collie D: Meningiomas. Lancet 363: 1535-1543, 2004

4. De Monte F: Current management of meningiomas. Oncology 9: 83-96, 1995.

5. Simpson D: The recurrence of intracranial meningiomas after surgical treatment. J Neurol Neurosurg Psychiatry 20: 22-39, 1957.
6. McCarthy BJ, Davis FG, Freels S, Surawicz TS, Damek DM, Grutsch J, Menck HR and Laws ER Jr: Factors associated with survival in patients with meningioma. J Neurosurg 88: 831-839, 1998.

7. Rogers L and Mehta M: Role of radiation therapy in treating intracranial meningiomas. Neurosurg Focus 23: E4, 2007.

8. Bajetto A, Bonavia R, Barbero S and Schettini G: Characterization of chemokines and their receptors in the central nervous system: physiopathological implications. J Neurochem 82: 1311-1329, 2002.

9. Teicher BA and Fricker SP: CXCL12(SDF-1)/CXCR4 pathway in cancer. Clin Cancer Res 16: 2927-2931, 2010.

10. Murphy PM: International Union of Pharmacology. XXX. Update on chemokine receptor nomenclature. Pharmacol Rev 54: 227-229, 2002

11. Nanki T, Shimaoka T, Hayashida K, Taniguchi K, Yonehara S and Miyasaka N: Pathogenic role of the CXCL16-CXCR6 pathway in rheumatoid arthritis. Arthritis Rheum 52: 3004-3014, 2005.

12. Sheikine Y and Sirsjö A: CXCL16/SR-PSOX - a friend or a foe in atherosclerosis? Atherosclerosis 197: 487-495, 2008.

13. Wågsäter D, Hugander A and Dimberg J: Expression of CXCL16 in human rectal cancer. Int J Mol Med 14: 65-69, 2004.

14. Ludwig A, Hundhausen C, Lambert MH, Broadway $\mathrm{N}$, Andrews RC, Bickett DM, Leesnitzer MA and Becherer JD: Metalloproteinase inhibitors for the disintegrin-like metalloproteinases ADAM10 and ADAM17 that differentially block constitutive and phorbol ester-inducible shedding of cell surface molecules. Comb Chem High Throughput Screen 8: 161-171, 2005.

15. Held-Feindt J, Rehmke B, Mentlein R, Hattermann K, Knerlich F, Hugo HH, Ludwig A and Mehdorn HM: Overexpression of CXCL16 and its receptor CXCR6/Bonzo promotes growth of human schwannomas. Glia 56: 764-774, 2008.

16. Darash-Yahana M, Gillespie JW, Hewitt SM, Chen YY, Maeda S, Stein I, Singh SP, Bedolla RB, Peled A, Troyer DA, Pikarsky E, Karin M and Farber JM: The chemokine CXCL16 and its receptor, CXCR6, as markers and promoters of inflammationassociated cancers. PLoS One 4: e6695, 2009.

17. Ludwig A and Mentlein R: Glial cross-talk by transmembrane chemokines CX3CL1 and CXCL16. J Neuroimmunol 198: 92-97, 2008.

18. Abel S, Hundhausen C, Mentlein R, Schulte A, Berkhout TA, Broadway N, Hartmann D, Sedlacek R, Dietrich S, Muetze B, Schuster B, Kallen KJ, Saftig P, Rose-John S and Ludwig A: The transmembrane CXC-chemokine ligand 16 is induced by IFN-gamma and TNF-alpha and shed by the activity of the disintegrin-like metalloproteinase ADAM10. J Immunol 172: 6362-6372, 2004.

19. Liu C, Luo D, Streit WJ and Harrison JK: CX3CL1 and CX3CR1 in the GL261 murine model of glioma: CX3CR1 deficiency does not impact tumor growth or infiltration of microglia and lymphocytes. J Neuroimmunol 198: 98-105, 2008.

20. Cardona AE, Pioro EP, Sasse ME, Kostenko V, Cardona SM, Dijkstra IM, Huang D, Kidd G, Dombrowski S, Dutta R, Lee JC, Cook DN, Jung S, Lira SA, Littman DR and Ransohoff RM: Control of microglial neurotoxicity by the fractalkine receptor. Nat Neurosci 9: 917-924, 2006.

21. Hojo S, Koizumi K, Tsuneyama K, Arita Y, Cui Z, Shinohara K, Minami T, Hashimoto I, Nakayama T, Sakurai H, Takano Y, Yoshie O, Tsukada K and Saiki I: High-level expression of chemokine CXCL16 by tumor cells correlates with a good prognosis and increased tumor-infiltrating lymphocytes in colorectal cancer. Cancer Res 67: 4725-4731, 2007.

22. Gutwein P, Schramme A, Sinke N, Abdel-Bakky MS, Voss B, Obermüller N, Doberstein K, Koziolek M, Fritzsche F, Johannsen M, Jung K, Schaider H, Altevogt P, Ludwig A, Pfeilschifter J and Kristiansen G: Tumoural CXCL16 expression is a novel prognostic marker of longer survival times in renal cell cancer patients. Eur J Cancer 45: 478-489, 2009.

23. Matsushita K, Toiyama Y, Tanaka K, Saigusa S, Hiro J, Uchida K, Inoue Y and Kusunoki M: Soluble CXCL16 in preoperative serum is a novel prognostic marker and predicts recurrence of liver metastases in colorectal cancer patients. Ann Surg Oncol 19 (Suppl 3): 518-527, 2012.

24. Ha HK, Lee W, Park HJ, Lee SD, Lee JZ and Chung MK: Clinical significance of CXCL16/CXCR6 expression in patients with prostate cancer. Mol Med Rep 4: 419-424, 2011.

25. Hattermann K, Ludwig A, Gieselmann V, Held-Feindt $\mathbf{J}$ and Mentlein R: The chemokine CXCL16 induces migration and invasion of glial precursor cells via its receptor CXCR6. Mol Cell Neurosci 39: 133-141, 2008. 
26. Bajetto A, Barbieri F, Dorcaratto A, Barbero S, Daga A Porcile C, Ravetti JL, Zona G, Spaziante R, Corte G, Schettini G and Florio T: Expression of CXC chemokine receptors 1-5 and their ligands in human glioma tissues: Role of CXCR4 and SDF1 in glioma cell proliferation and migration. Neurochem Int 49: 423-432, 2006.

27. Rodero M, Marie Y, Coudert M, Blondet E, Mokhtari K, Rousseau A, Raoul W, Carpentier C, Sennlaub F, Deterre P, Delattre J-Y, Debré P, Sanson M and Combadière C: Polymorphism in the microglial cell-mobilizing CX3CR1 gene is associated with survival in patients with glioblastoma. J Clin Oncol 26: 5957-5964, 2008.

28. Xin H, Kikuchi T, Andarini S, Ohkouchi S, Suzuki T, Nukiwa T, Huqun, Hagiwara K, Honjo T and Saijo Y: Antitumor immune response by CX3CL1 fractalkine gene transfer depends on both NK and T cells. Eur J Immunol 35: 1371-1380, 2005.

29. Yu YR, Fong AM, Combadiere C, Gao JL, Murphy PM and Patel DD: Defective antitumor response in CX3CR1-deficient mice. Int J Cancer 121: 316-322, 2007.

30. Imai T, Hieshima K, Haskell C, Baba M, Nagira M, Nishimura M, Kakizaki M, Takagi S, Nomiyama H, Schall TJ and Yoshie O: Identification and molecular characterization of fractalkine receptor CX3CR1, which mediates both leukocyte migration and adhesion. Cell 91: 521-530, 1997.

31. Combadiere C, Salzwedel K, Smith ED, Tiffany HL, Berger EA and Murphy PM: Identification of CX3CR1. A chemotactic receptor for the human $\mathrm{CX} 3 \mathrm{C}$ chemokine fractalkine and a fusion coreceptor for HIV-1. J Biol Chem 273: 23799-23804, 1998.

32. Ludwig A and Weber C: Transmembrane chemokines: versatile 'special agents' in vascular inflammation. Thromb Haemost 97: 694-703, 2007.

33. Unutmaz D, Xiang W, Sunshine MJ, Campbell J, Butcher E and Littman DR: The primate lentiviral receptor Bonzo/STRL33 is coordinately regulated with CCR5 and its expression pattern is conserved between human and mouse. J Immunol 165 3284-3292, 2000

34. Matloubian M, David A, Engel S, Ryan JE and Cyster JG: A transmembrane CXC chemokine is a ligand for HIV-coreceptor Bonzo. Nat Immunol 1: 298-304, 2000.

35. Geissmann F, Cameron TO, Sidobre S, Manlongat N, Kronenberg M, Briskin MJ, Dustin ML and Littman DR: Intravascular immune surveillance by $\mathrm{CXCR}^{+}$NKT cells patrolling liver sinusoids. PLoS Biol 3: e113, 2005.

36. Tong Y, Mentlein R, Buhl R, Hugo H-H, Mehdorn HM and HeldFeindt J: Overexpression of midkine contributes to anti-apoptotic effects in human meningiomas. J Neurochem 100: 1097-1107, 2007.

37. Homey B, Müller A and Zlotnik A: Chemokines: agents for the immunotherapy of cancer? Nat Rev Immunol 2: 175-184, 2002.

38. Harrison JK, Jiang Y, Chen S, Xia Y, Maciejewski D McNamara RK, Streit WJ, Salafranca MN, Adhikari S, Thompson DA, Botti P, Bacon KB and Feng L: Role for neuronally derived fractalkine in mediating interactions between neurons and CX3CR1-expressing microglia. Proc Natl Acad Sci USA 95: 10896-10901, 1998.

39. Hatori K, Nagai A, Heisel R, Ryu JK and Kim SU: Fractalkine and fractalkine receptors in human neurons and glial cells. $J$ Neurosci Res 69: 418-426, 2002.

40. Miller RJ, Rostene W, Apartis E, Banisadr G, Biber K, Milligan ED, White FA and Zhang J: Chemokine action in the nervous system. J Neurosci 28: 11792-11795, 2008.

41. Mizuno T, Kawanokuchi J, Numata K and Suzumura A: Production and neuroprotective functions of fractalkine in the central nervous system. Brain Res 979: 65-70, 2003.
42. Held-Feindt J, Hattermann K, Müerköster SS, Wedderkopp H, Knerlich-Lukoschus F, Ungefroren H, Mehdorn HM and Mentlein R: CX3CR1 promotes recruitment of human gliomainfiltrating microglia/macrophages (GIMs). Exp Cell Res 316 : 1553-1566, 2010.

43. Guo J, Chen T, Wang B, Zhang M, An H, Guo Z, Yu Y, Qin Z and Cao X: Chemoattraction, adhesion and activation of natural killer cells are involved in the antitumor immune response induced by fractalkine/CX3CL1. Immunol Lett 89: 1-7, 2003.

44. Guo J, Zhang M, Wang B, Yuan Z, Guo Z, Chen T, Yu Y, Qin Z and Cao X: Fractalkine transgene induces T-cell-dependent antitumor immunity through chemoattraction and activation of dendritic cells. Int J Cancer 103: 212-220, 2003.

45. Lavergne E, Combadière B, Bonduelle O, Iga M, Gao JL, Maho M, Boissonnas A, Murphy PM, Debré $\mathrm{P}$ and Combadière C: Fractalkine mediates natural killer-dependent antitumor responses in vivo. Cancer Res 63: 7468-7474, 2003.

46. Tang L, Hu HD, Hu P, Lan YH, Peng ML, Chen M and Ren $\mathrm{H}$ Gene therapy with CX3CL1/Fractalkine induces antitumor immunity to regress effectively mouse hepatocellular carcinoma. Gene Ther 14: 1226-1234, 2007.

47. Matsubara T, Ono T, Yamanoi A, Tachibana M and Nagasue $\mathrm{N}$ : Fractalkine-CX3CR1 axis regulates tumor cell cycle and deteriorates prognosis after radical resection for hepatocellular carcinoma. J Surg Oncol 95: 241-249, 2007.

48. Scholz F, Schulte A, Adamski F, Hundhausen C, Mittag J, Schwarz A, Kruse ML, Proksch E and Ludwig A: Constitutive expression and regulated release of the transmembrane chemokine CXCL16 in human and murine skin. J Invest Dermatol 127: 1444-1455, 2007.

49. le Blanc LM, van Lieshout AW, Adema GJ, van Riel PL, Verbeek MM and Radstake TR: CXCL16 is elevated in the cerebrospinal fluid versus serum and in inflammatory conditions with suspected and proved central nervous system involvement. Neurosci Lett 397: 145-148, 2006.

50. Shimaoka T, Nakayama T, Fukumoto N, Kume N, Takahashi S, Yamaguchi J, Minami M, Hayashida K, Kita T, Ohsumi J, Yoshie $\mathrm{O}$ and Yonehara S: Cell surface-anchored SR-PSOX/CXC chemokine ligand 16 mediates firm adhesion of CXC chemokine receptor 6-expressing cells. J Leukoc Biol 75: 267-274, 2004.

51. Hase K, Murakami T, Takatsu H, Shimaoka T, Iimura M, Hamura K, Kawano K, Ohshima S, Chihara R, Itoh K, Yonehara S and Ohno $\mathrm{H}$ : The membrane-bound chemokine CXCL16 expressed on follicle-associated epithelium and $\mathrm{M}$ cells mediates lympho-epithelial interaction in GALT. J Immunol 176: 43-51, 2006.

52. Matsumura S, Wang B, Kawashima N, Braunstein S, Badura M, Cameron TO, Babb JS, Schneider RJ, Formenti SC, Dustin ML and Demaria S: Radiation-induced CXCL16 release by breast cancer cells attracts effector T cells. J Immunol 181: 3099-3107, 2008.

53. Hu W, Zhen X, Xiong B, Wang B, Zhang W and Zhou W: CXCR6 is expressed in human prostate cancer in vivo and is involved in the in vitro invasion of PC3 and LNCap cells. Cancer Sci 99: 1362-1369, 2008.

54. Wente MN, Gaida MM, Mayer C, Michalski CW, Haag N, Giese T, Felix K, Bergmann F, Giese NA and Friess H: Expression and potential function of the CXC chemokine CXCL16 in pancreatic ductal adenocarcinoma. Int J Oncol 33: 297-308, 2008.

55. Gaida MM, Günther F, Wagner C, Friess H, Giese NA, Schmidt J, Hänsch GM and Wente MN: Expression of the CXCR6 on polymorphonuclear neutrophils in pancreatic carcinoma and in acute, localized bacterial infections. Clin Exp Immunol 154: 216-223, 2008. 